\title{
Uniform, Binary Functionalization of a Metal-Organic Framework Material
}

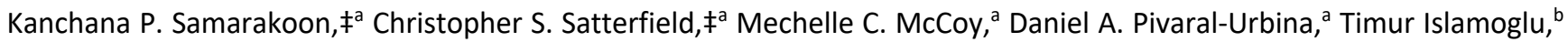
Victor W. Dayc and Tendai Gadzikwa*a

aDepartment of Chemistry, Kansas State University, Manhattan, Kansas 66506, USA

bDepartment of Chemistry, Northwestern University, 2145 Sheridan Road, Evanston, Illinois 60208, USA

'X-Ray Crystallography Lab, University of Kansas, Law-rence, Kansas, 66045, USA

Email: gadzikwa@ksu.edu

MATERIALS

SYNTHETIC PROCEDURES.

CHARACTERIZATION

Powder X-ray diffraction (PXRD)

Proton nuclear magnetic resonance ( ${ }^{1} \mathrm{H}$ NMR)

Nitrogen gas adsorption/desorption

Thermogravimetric analysis (TGA)

Electrospray lonization Mass Spectrometry (ESI)

Fourier-transform infrared spectroscopy (FTIR)

Single-crystal X-ray crystallography analysis for KSU-1. 


\section{MATERIALS}

All chemicals were used as received from commercial sources unless otherwise noted. Meso- $\alpha, \beta$-di(4pyridyl) glycol (DPG) was purchased from TCl. Butyric anhydride and 2-aminoterephthalic acid (BDC- $\mathbf{N H}_{2}$ ) were purchased from Alpha Aesar. Succinic anhydride and sulfuric acid- $d_{2}\left(\mathrm{D}_{2} \mathrm{SO}_{4}, 98 \mathrm{wt} \%\right.$ in $\mathrm{D}_{2} \mathrm{O}, 99.5+\%$ atom D) were purchased from Acros Organics. N,N-dimethylformamide (DMF) was purchased from Fisher Scientific, and zinc nitrate hexahydrate from Strem Chemicals. Anhydrous chloroform $\left(\mathrm{CHCl}_{3}\right)$ was purchased from Sigma Aldrich, and 1,4-Diazabicyclo[2.2.2]octane (DABCO) from Oakwood Products. Dimethyl sulfoxide- $d_{6}\left(d_{6}\right.$-DMSO, 99.9 atom \% D) was purchased from Cambridge Isotopes Laboratories.

\section{SYNTHETIC PROCEDURES.}

Synthesis of KSU-1. $\mathrm{Zn}\left(\mathrm{NO}_{3}\right)_{2} \cdot 6 \mathrm{H}_{2} \mathrm{O}(95.2 \mathrm{mg}, 0.32 \mathrm{mmol})$, DPG (106 mg. $\left.0.49 \mathrm{mmol}\right)$, and DMF (80 mL) were combined in a $500 \mathrm{~mL}$ Florence flask. The flask was heated at $60^{\circ} \mathrm{C}$ in a $500 \mathrm{~mL}$ heating block until the solution became clear. A solution of BDC- $\mathrm{NH}_{2}(90.6 \mathrm{mg}, 0.50 \mathrm{mmol})$ in DMF $(20 \mathrm{~mL})$ was added, and the flask incubated at $60^{\circ} \mathrm{C}$. After $48 \mathrm{~h}$, the flask was removed from the heating block and left at room temperature for $48 \mathrm{~h}$. Pale yellow crystals ( $40 \mathrm{mg}, 35 \%$ yield) of the product were collected by filtration after several $\sim 30$ min washings with DMF.

General Procedure for the reaction of KSU-1 with butyric anhydride (Synthesis of KSU-1 mono). Following a modified literature procedure, ${ }^{1} \mathrm{KSU}-1$ ( $50 \mathrm{mg}, 0.0708 \mathrm{mmol}$, ca. $0.142 \mathrm{mmol}$ equiv of $-\mathrm{NH}_{2}$ ) was transferred into a $10 \mathrm{~mm}$ diameter glass exchange thimble with a glass frit that was placed into a $20 \mathrm{~mL}$ scintillation vial. The vial was charged with $10 \mathrm{~mL}$ of a $0.05 \mathrm{M}$ solution of butyric anhydride (4 equiv.) in anhydrous $\mathrm{CHCl}_{3}$, and the mixture was left at room temperature for $24 \mathrm{~h}$ with continuous mixing on a Corning LSE Low Speed Orbital Shaker. The glass thimble containing the MOF material was then transferred to a new scintillation with $10 \mathrm{~mL}$ of a $0.025 \mathrm{M}$ solution of butyric anhydride (2 equiv.) in anhydrous $\mathrm{CHCl}_{3}$, and left to mix for another $24 \mathrm{~h}$. The reactant solution was exchanged this way 2 more times, each after $24 \mathrm{~h}$. The thimble containing the MOF material was then transferred to a new scintillation vial containing fresh $\mathrm{CHCl}_{3}$ and mixed for $\sim 30 \mathrm{~min}$. The $\mathrm{CHCl}_{3}$ was exchanged with fresh $\mathrm{CHCl}_{3} 3$ times, and then fresh DMF a further 3 times. Pale yellow crystals were isolated from the frit (93\% yield) and stored under DMF.

General Procedure for the nucleophilic ring-opening of succinic anhydride by KSU-1 mono (Synthesis of KSU-1 bi). Following a modified literature procedure, ${ }^{1} \mathrm{KSU}-\mathbf{1}_{\mathrm{mono}}(50 \mathrm{mg}, 0.0593 \mathrm{mmol}, \mathrm{ca} .0 .118 \mathrm{mmol}$ equiv of $-\mathrm{OH}$ ) was transferred into a $10 \mathrm{~mm}$ diameter glass exchange thimble with glass frit, that was placed into a $20 \mathrm{~mL}$ scintillation vial that had been charged with a suspension of succinic anhydride ( $80 \mathrm{mg}, 6$ equiv.) in $4 \mathrm{~mL}$ of anhydrous $\mathrm{CHCl}_{3}$. The mixture was left at room temperature for $72 \mathrm{~h}$ with continuous mixing on a Corning LSE Low Speed Orbital Shaker. The thimble containing the MOF material was then transferred to a new scintillation vial containing fresh $\mathrm{CHCl}_{3}$ and mixed for $\sim 30 \mathrm{~min}$. The $\mathrm{CHCl}_{3}$ was exchanged with fresh $\mathrm{CHCl}_{3} 3$ more times, and then fresh DMF a further 3 times. Pale yellow crystals were isolated from the frit (88\% yield) and stored under DMF. 


\section{CHARACTERIZATION}

\section{Powder X-ray diffraction (PXRD)}

Powder patterns were recorded on a Bruker AXS D8 Advance Phaser diffractometer with Cu Ka radiation $(\lambda$ $=1.5418 \AA$ ) over a range of $5^{\circ}<2 \theta<40^{\circ}$ in $0.02^{\circ}$ steps with a $0.5 \mathrm{~s}$ counting time per step. Samples were collected from the bottom of the reaction vial as a thick suspension in DMF and spread on a Si-Einkristalle plate immediately before PXRD measurements.

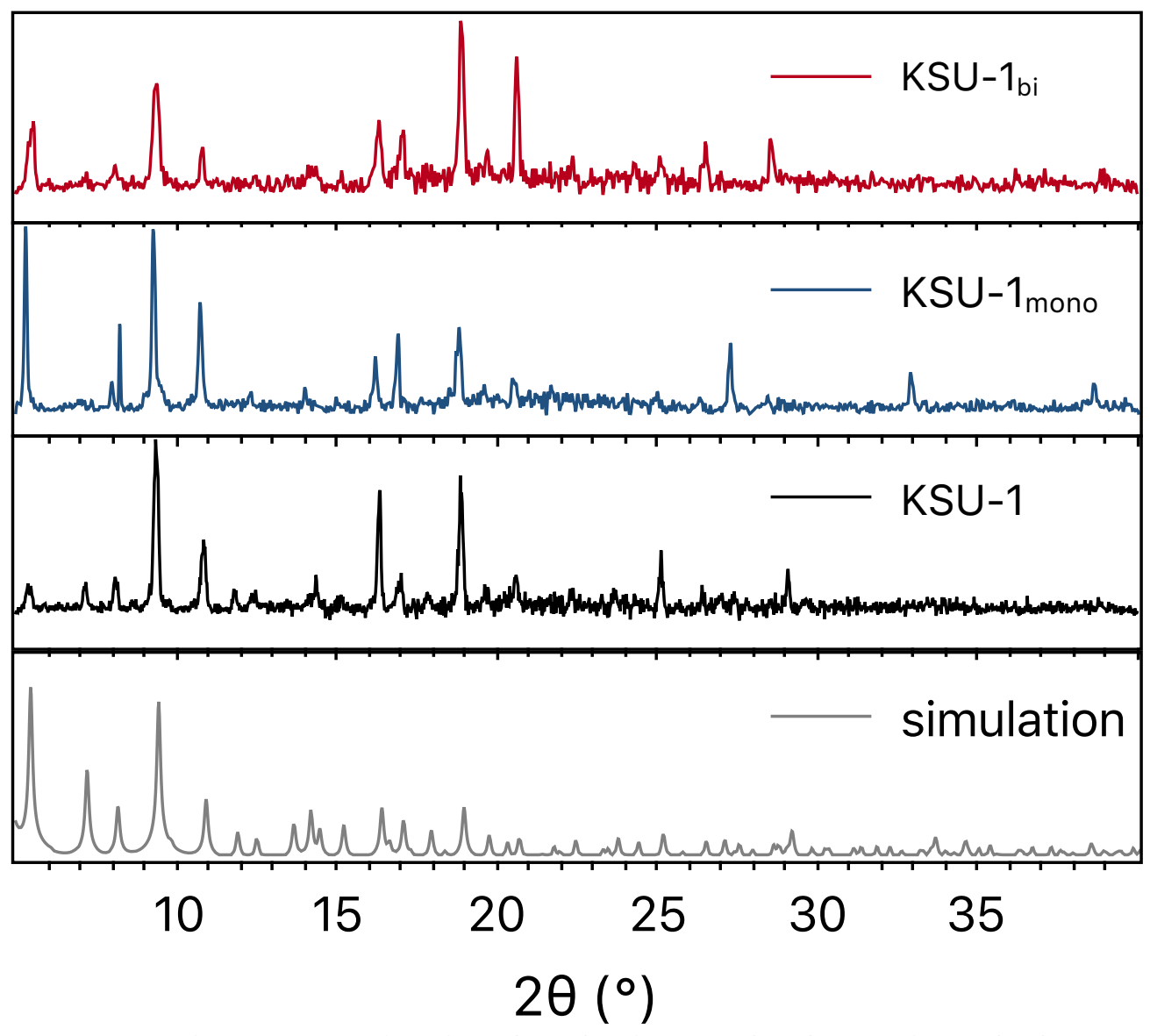

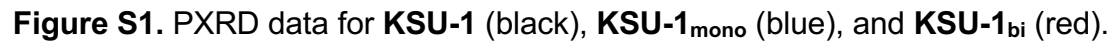




\section{Proton nuclear magnetic resonance ( ${ }^{1} \mathrm{H}$ NMR)}

Spectra were recorded on a Varian $400 \mathrm{MHz}$ NMR spectrometer $\left(400 \mathrm{MHz}\right.$ for $\left.{ }^{1} \mathrm{H}\right)$. NMR chemical shifts are reported in ppm against a residual solvent resonance as the internal standard $\left(\delta\left(d_{6}-\mathrm{DMSO}\right)=2.5 \mathrm{ppm}\right)$. In a typical analysis, MOF materials stored in DMF were solvent exchanged with $\mathrm{CHCl}_{3}$, isolated by vacuum filtration, and then evacuated in a vacuum oven at $80{ }^{\circ} \mathrm{C}$ overnight. Evacuated MOF samples ( $\left.8 \mathrm{mg}\right)$ were transferred into an NMR tube and $d_{6}$-DMSO $(0.5 \mathrm{~mL})$ was added. Subsequently, $\mathrm{D}_{2} \mathrm{SO}_{4}(0.05 \mathrm{~mL}, 98 \% \mathrm{w} / \mathrm{w}$ in $\mathrm{D}_{2} \mathrm{O}$ ) or DABCO (10 mg; $\left.178 \mathrm{mM}\right)$ was also added. The tubes were capped and sonicated until all the solid was dissolved ( $1 \mathrm{~min})$.
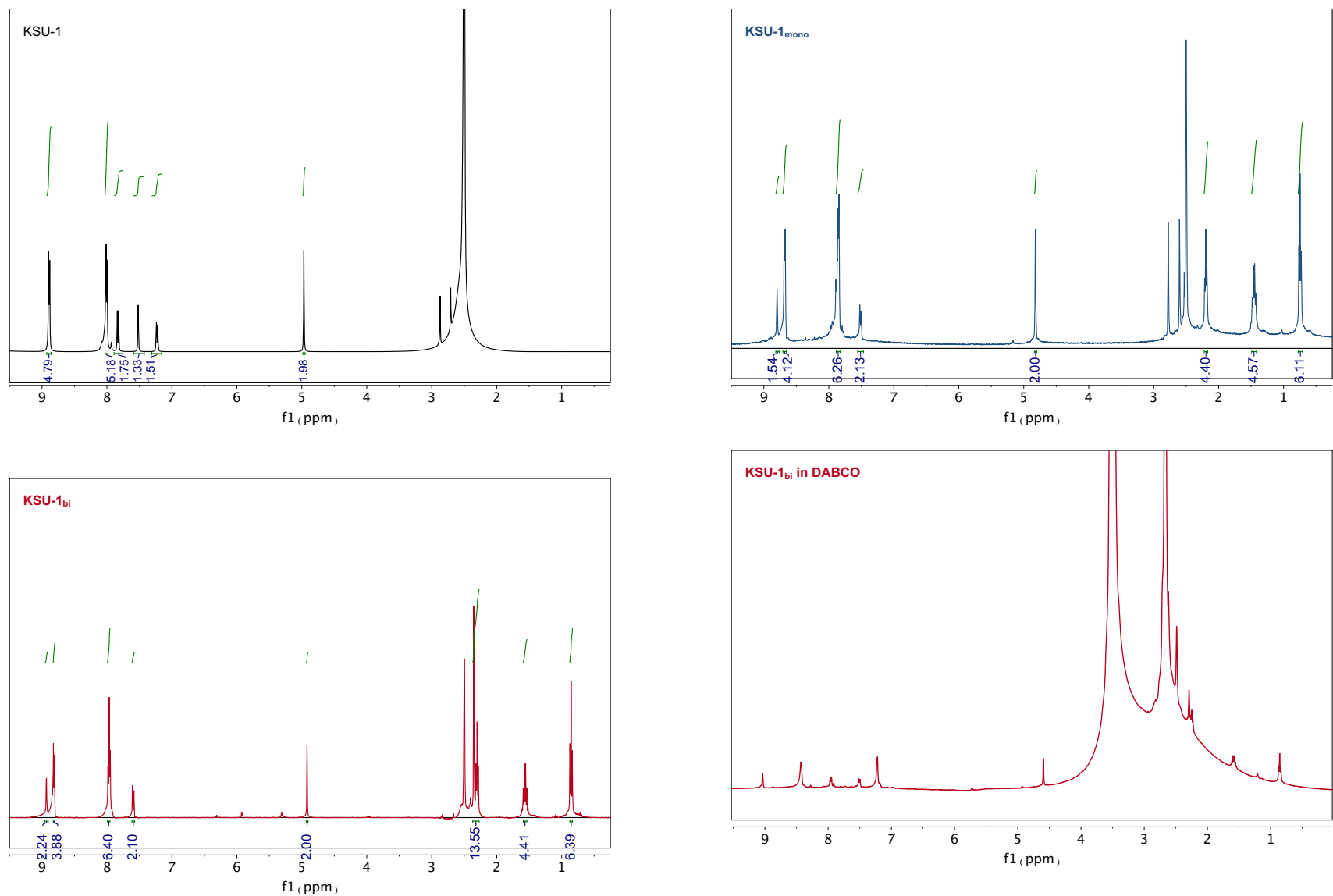

Figure S2. Integrated ${ }^{1} \mathrm{H}-\mathrm{NMR}$ spectrum for $\mathrm{KSU}-\mathbf{1}, \mathbf{K S U}-\mathbf{1}_{\text {mono, }}$ and $\mathbf{K S U}-\mathbf{1}_{\mathbf{b i}}$ digested in $\mathrm{D}_{2} \mathrm{SO}_{4} / d_{6}-\mathrm{DMSO}$, and ${ }^{1} \mathrm{H}-\mathrm{NMR}$ spectrum of KSU-1 $\mathbf{b i}_{\mathbf{b i}}$ digested in $\mathrm{DABCO} / \mathrm{d}_{6}-\mathrm{DMSO}$. 


\section{Nitrogen gas adsorption/desorption}

Measurements were performed on a Micromeritics Tristar II 3020 (Micromeritics, Norcross, GA) at $77 \mathrm{~K}$ on samples that underwent supercritical $\mathrm{CO}_{2}$ drying. Supercritical $\mathrm{CO}_{2}$ drying was performed using a Tousimis Samdri PVT-30 critical point dryer (Tousimis, Rockville, MD, USA). Supercritically dried samples were prepared in the following manner: MOF materials that had undergone DMF to hexanes solvent exchanges were again solvent exchanged with ethanol by two quick washes. The ethanol-dispersed samples were transferred into the sample holder with a glass pipet and allowed to settle down. Excess EtOH was pipetted out and the sample holder was placed into a Tousimis Samdri-PVT-3D supercritical $\mathrm{CO}_{2}$ dryer. The temperature was lowered to $0{ }^{\circ} \mathrm{C}$, and the chamber was filled with liquid $\mathrm{CO}_{2}$ (ultrahigh grade $\mathrm{CO}_{2}$ with a siphon from Air-Gas Inc). The sample was soaked for 8 hours total, venting for five minutes every two hours. The chamber was then heated to $40^{\circ} \mathrm{C}$, and the supercritical $\mathrm{CO}_{2}$ was bled off at a rate of $0.25 \mathrm{~mL} / \mathrm{min}$ until the chamber reached ambient pressure (typically overnight). The chamber was opened and the sample was quickly transferred into a pre-weighed glass sample tube which was sealed and quickly transferred to a system providing 10-4 torr dynamic vacuum.
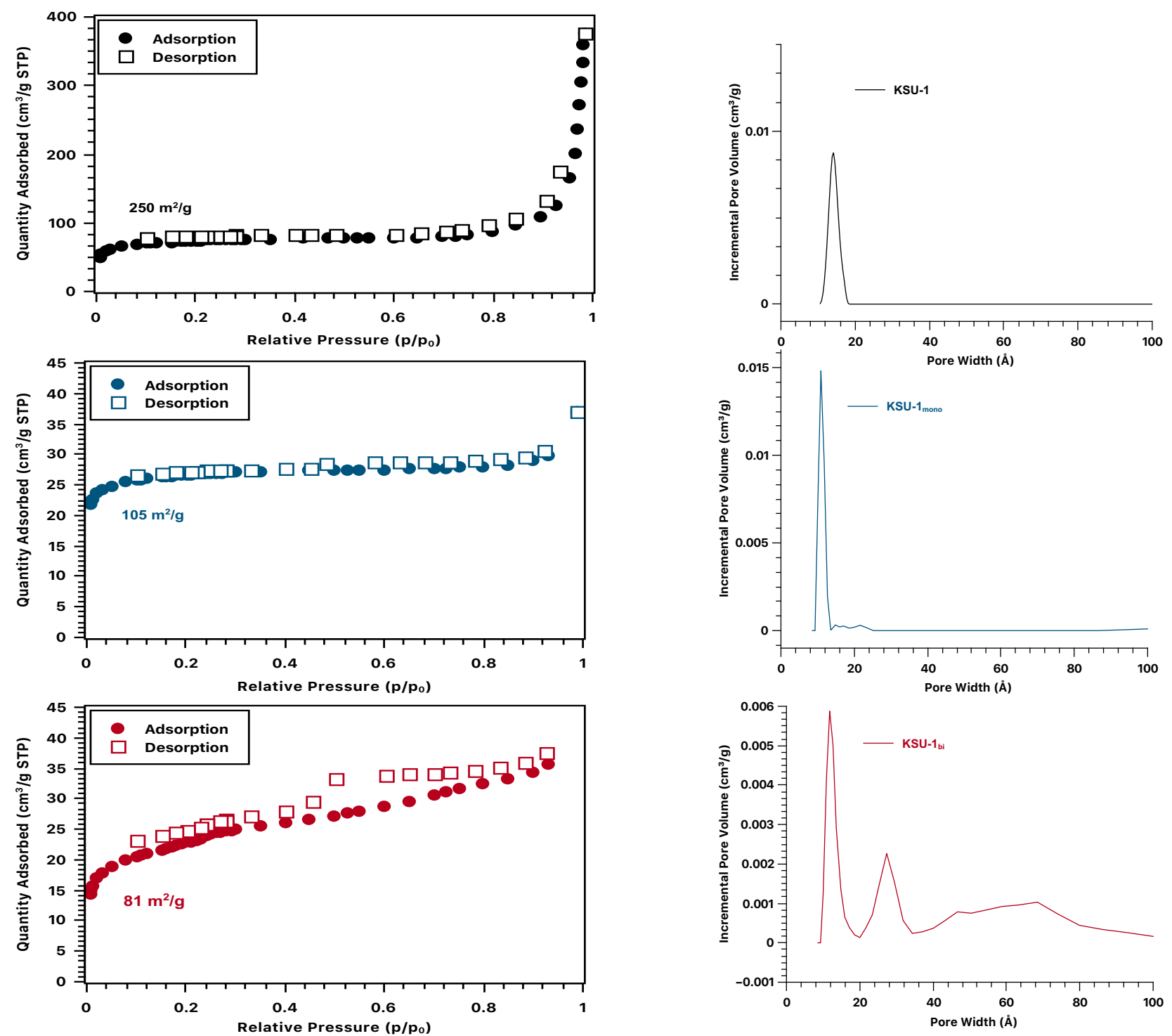

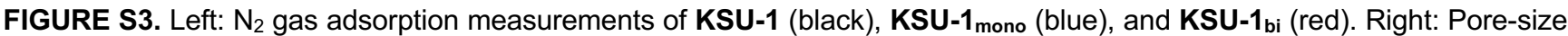
distributions of KSU-1 (black), KSU-1 mono (blue), and KSU-1 
Thermogravimetric analysis (TGA)

TGA was performed on a TGA-Q50 interfaced with a PC using TA Universal Analysis software. Samples were heated at a rate of $10{ }^{\circ} \mathrm{C} / \mathrm{min}$ under a nitrogen atmosphere. All samples were extensively solvent exchanged with fresh DMF prior to analysis.

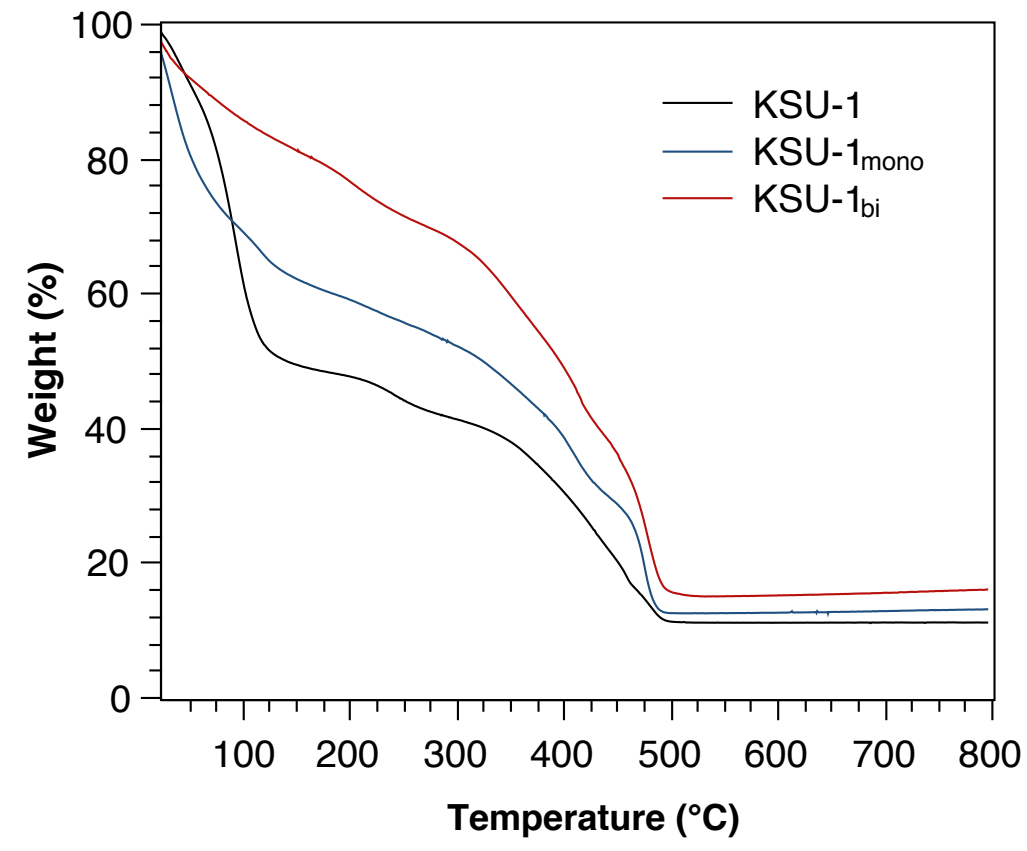

Figure S4. TGA data for KSU-1 (black), KSU -1 mono (blue), and KSU-1 bi $_{\text {(red). }}$ 


\section{Electrospray lonization Mass Spectrometry (ESI)}

MOF samples $(\sim 5 \mathrm{mg})$ were placed in a solution of DABCO $(10 \mathrm{mg})$ and $0.25 \mathrm{ml}$ of DMSO in a 2-dram vial. The vial was sonicated for $\sim 1 \mathrm{~min}$ then heated at $80^{\circ} \mathrm{C}$ overnight. A small amount of residue was filtered out and resulting solution was sent for ESI-MS analysis at the Mass Spectrometry Laboratory at the University of Illinois, Urbana-Champaign.

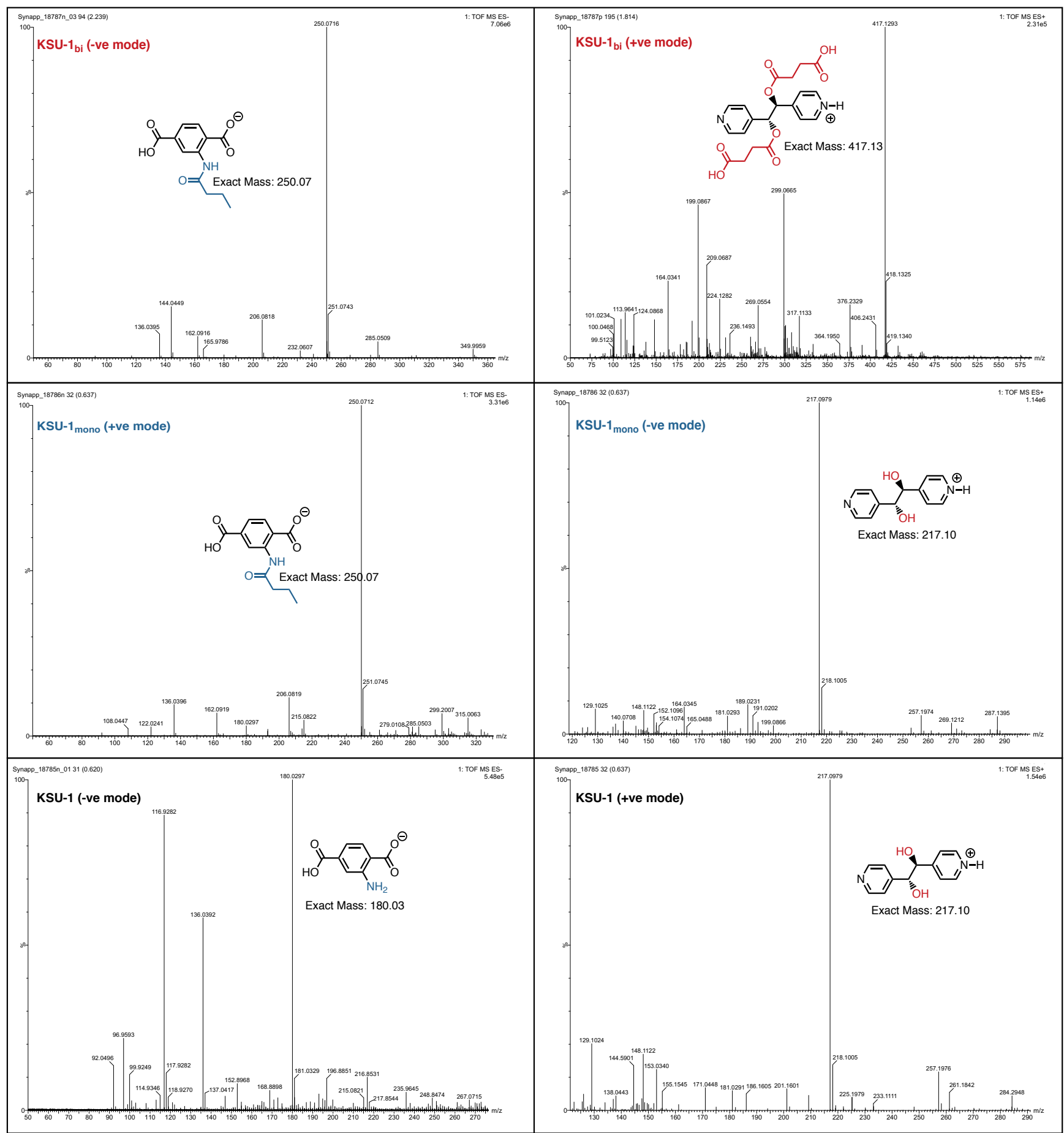

FIGURE S5. High-resolution electrospray ionization mass spectrometry (ESI-MS) of KSU-1 (bottom), KSU-1 mono (middle), and KSU-1 $\mathbf{b i}_{\mathbf{b i}}$ (top) in negative (left) and positive (right) mode. 


\section{Fourier-transform infrared spectroscopy (FTIR)}

Fourier-transform infrared spectroscopy was performed on a Cary 630 spectrometer. Spectra were collected on MOF samples $(\sim 1 \mathrm{mg})$ which had combined with an equivalent amount $(\sim 1 \mathrm{mg})$ of $\mathrm{KBr}$ and ground together to a fine powder.

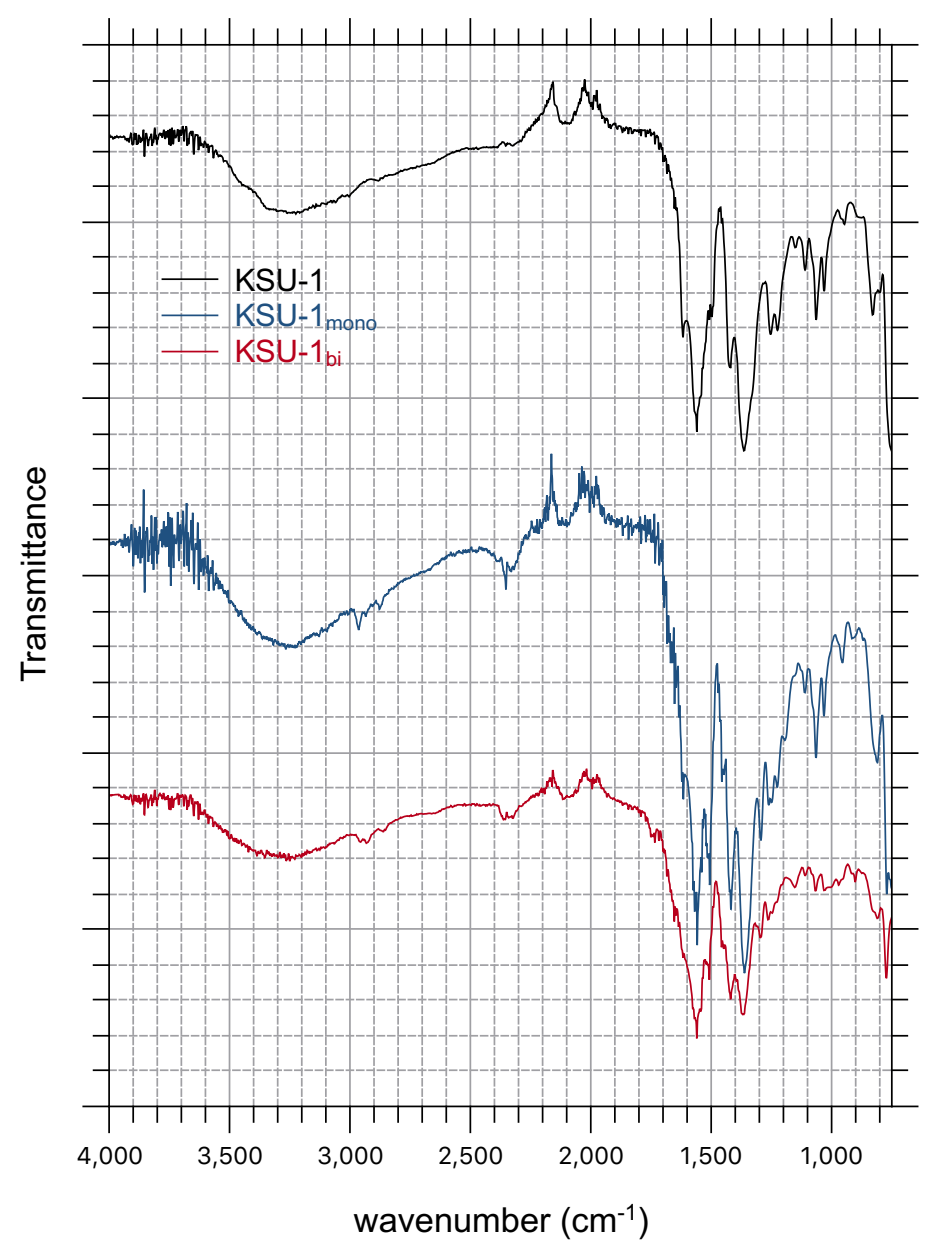

FIGURE S6. Fourier-transform infrared spectroscopy (FT-IR) of KSU-1 (top), KSU-1 mono (middle), and KSU-1 bi (bottom) 


\section{Single-crystal X-ray crystallography analysis for KSU-1.}

A set of diffraction data [85166 reflections using $39321^{\circ}$-wide $\omega$ - or $\phi$-scan frames with scan times of 515 seconds] was collected ${ }^{2}$ for a single-domain crystal of KSU-1 using monochromated CuK $\alpha$ radiation $(\lambda=$ $1.54178 \AA$ ) on a Bruker Proteum Single Crystal Diffraction System with dual CCD detectors and associated Helios high-brilliance multilayer optics and a shared Bruker MicroSTAR microfocus Cu rotating anode $x$-ray source operating at $45 \mathrm{kV}$ and $60 \mathrm{~mA}$. Data for KSU-1 was collected with an Apex II CCD detector and a crystal-to-detector distance of $50 \mathrm{~mm}$. The integrated data ${ }^{3}$ were corrected empirically for variable absorption effects using equivalent reflections. The Bruker software package SHELXTL was used to solve the structure using "direct methods" techniques. All stages of weighted full-matrix least-squares refinement were conducted using $\mathrm{F}_{0}{ }^{2}$ data with the SHELXTL XL v2014 software package. ${ }^{4}$ Final crystallographic details are summarized in Table S1.

The asymmetric unit of $\mathbf{K S U}-1$ contains two $\mathrm{Zn}^{2+}$ cations, two 3-aminoterephthalate (BDC-NH ) dianions and one neutral meso- $\alpha, \beta-d i(4-p y r i d y l)$ glycol (DPG) moiety. Although disorder is common and not unexpected in MOF structures, the bridging ligands in this particular system have additional potential for inherent disorder. While octahedral coordination at the $\mathrm{Zn}$ ions will preclude much rotational disorder of the planar BDC-NH ligands about the $\mathrm{Zn} \cdots \cdot \mathrm{Nn}^{\mathrm{Zn}}$ vector, each "locked" ligand can still bridge the same two $\mathrm{Zn}$ metals in four different ways. Since the DPG ligand coordinates to a $\mathrm{Zn}$ atom through a single nitrogen on each end, it could have different rotational orientations about the $\mathrm{Zn} \cdots \cdot \bullet \mathrm{Zn}$ vector. The ligand could also bridge the same two metals with its two ends interchanged. Fortunately, both of the BDC-NH $\mathbf{N}_{2}$ ligands appear to have only two of the four possible orientations and the DPG ligand does not appear to be have significant rotational disorder about the $\mathrm{Zn} \cdot \cdots \cdot \mathrm{Zn}$ vector.

Fourier maps from the initial structure solution clearly revealed the $\mathrm{Zn}$ atoms, all $\mathrm{C}$ and $\mathrm{O}$ atoms of the BDC- $\mathrm{NH}_{2}$ ligands and the $\mathrm{C}$ and $\mathrm{N}$ atoms of the pyridine rings for the DPG ligand. Non-structured (presumably disordered) electron density was present between the two DPG pyridine rings. Cycles of least squares refinement were then performed using anisotropic thermal parameters for the $\mathrm{Zn}$ atoms and the BDC-NH $\mathbf{N H}_{2} \mathrm{C}$ and $\mathrm{O}$ atoms and isotropic thermal parameters for the DPG pyridine $\mathrm{C}$ and $\mathrm{N}$ atoms. A difference Fourier revealed low electron density at $s p^{2}$-hybridized positions for two ortho (4- and 7-) carbons of both BDC- $\mathbf{N H}_{2}$ ligands. It also contained a more structured region of electron density between the two coordinated pyridine ligands that indicated two linking modes for the ligand with the coordinating ends interchanged. Two ortho-nitrogen atoms were included to the structural model for each $\mathbf{B D C}-\mathbf{N H}_{2}$ ligand; they were included with anisotropic thermal parameters and variable occupancy factors that refined to final normalized values of 0.65 and 0.35 for each ligand.

The published structure of DPG ${ }^{5}$ was then used with the coordinates of the two pyridine ligands and the disordered electron density between them to derive coordinates for two linking modes for the DPG ligand in KSU-1. Bond lengths and angles for the atoms of these DPG linking modes were required to have values similar to the published structure ${ }^{5}$. The bond lengths and angles were restrained to idealized $s p^{2}-$ or $s p^{3}$ hybridized multiples of the aromatic $\mathrm{C}=\mathrm{C}$ bond length that was included in the refinement as a free variable; it refined to a final value of 1.306(3) $\AA$. All four of the 7-atom $p$-methylpyridine moieties were also required to be coplanar. The normalized occupancy factors for the DPG linkers refined to $45 \% / 55 \%$.

Mild restraints had to eventually be applied to the anisotropic thermal parameters for two of the partialoccupancy BDC-NH2 nitrogen atoms (N23 and N27). Although these amine nitrogen atoms were disordered, they refined well with restrained anisotropic thermal parameters. Since all of the DPG nonhydrogen atoms linking the pyridine rings were disordered and not well-defined, the DPG ligand nonhydrogen atoms were included in the structural model with isotropic thermal parameters. When thermal parameters for six of the disordered DPG nonhydrogen atoms refined to unreasonably high values, they were fixed at values closer to those of their neighbors. Hydrogen atoms bonded to carbon in all ligands were included in the structural model as idealized riding model atoms (assuming or $\mathrm{sp}^{2}$ - or $\mathrm{sp}^{3}$-hybridization of the carbon atoms and $\mathrm{C}-\mathrm{H}$ bond lengths of $0.95 \AA$ or $1.00 \AA$ ). Hydrogen atoms bonded to nitrogen or oxygen were omitted. The isotropic thermal parameters of idealized hydrogen atoms in all ligands were fixed at values 1.2 times the equivalent isotropic thermal parameter of the carbon atom to which they are covalently bonded. Low residual difference Fourier electron density appearing at reasonable positions in the MOF channels was included in the structural model as half-occupancy isotropic oxygen atoms that still did not completely fill the structural voids. Refinement of racemic twinning revealed the crystal was a 65/35 racemic twin. 
Table S1. Crystal and Refinement Data KSU-1.

\begin{tabular}{|c|c|}
\hline & KSU-1 \\
\hline Empirical formula & $\mathrm{C}_{28.00} \mathrm{H}_{14.00} \mathrm{~N}_{4.00} \mathrm{O}_{16.32} \mathrm{Zn}_{2.00}$ \\
\hline Formula weight & 299.44 \\
\hline Temperature & $200(2) \mathrm{K}$ \\
\hline Wavelength & $1.54178 \AA$ \\
\hline Crystal system & Trigonal \\
\hline Space group & $\mathrm{P} 3-\mathrm{C}_{3}^{1}$ (No. 143$)$ \\
\hline$a$ & $21.5814(4) \AA$ \\
\hline$b$ & $21.5814(4) \AA$ \\
\hline$c$ & $16.1592(3) \AA$ \\
\hline$a$ & $90.00^{\circ}$ \\
\hline$\beta$ & $90.00^{\circ}$ \\
\hline$\gamma$ & $120.00^{\circ}$ \\
\hline Volume & $6517.9(3) \AA^{3}$ \\
\hline Z & 3 \\
\hline Density (calculated) & $0.610 \mathrm{~g} / \mathrm{cm}^{3}$ \\
\hline Absorption coefficient & $0.956 \mathrm{~mm}^{-1}$ \\
\hline$F(000)$ & 1202 \\
\hline Crystal size & $0.050 \times 0.050 \times 0.040 \mathrm{~mm}^{3}$ \\
\hline Theta range & 2.36 to $70.52^{\circ}$ \\
\hline Index ranges & $\begin{array}{l}-25 \leq h \leq 26,-24 \leq k \leq 26,- \\
14 \leq 1 \leq 19\end{array}$ \\
\hline Reflections collected & 85166 \\
\hline Independent reflections & $14685\left[R_{\text {int }}=0.064\right]$ \\
\hline Completeness to $\theta=66^{\circ}$ & $99.9 \%$ \\
\hline Absorption correction & Multi-scan \\
\hline Max. and min. transmission & 1.000 and 0.756 \\
\hline Refinement method & $\begin{array}{l}\text { Full-matrix least-squares on } \\
\mathrm{F}^{2}\end{array}$ \\
\hline Data / restraints / parameters & 14685 / 107 / 454 \\
\hline Goodness-of-fit on $\mathrm{F}^{2}$ & 1.062 \\
\hline Final $R$ indices $[\mid>2 \sigma(I)]$ & $\mathrm{R}_{1}=0.108, \mathrm{wR}_{2}=0.278$ \\
\hline $\mathrm{R}$ indices (all data) & $\mathrm{R}_{1}=0.141, \mathrm{wR}_{2}=0.331$ \\
\hline Largest diff. peak and hole & 1.26 and $-1.09 e^{-/} / \AA^{3}$ \\
\hline
\end{tabular}




\section{REFERENCES}

(1) Garibay, S. J.; Wang, Z.; Tanabe, K. K.; Cohen, S. M. Postsynthetic Modification: A Versatile Approach Toward Multifunctional Metal-Organic Frameworks. Inorg. Chem. 2009, 48 (15), 7341-7349.

(2) Data Collection: SMART Software in APEX2 V2014.11-0 Suite. Bruker-AXS, 5465 E. Cheryl Parkway, Madison, WI 53711-5373 USA.

(3) Data Reduction: SAINT Software in APEX2 V2014.11-0 Suite. Bruker-AXS, 5465 E. Cheryl Parkway, Madison, WI 53711-5373 USA.

(4) Refinement: SHELXTL Software in APEX2 V2014.11-0 Suite. Bruker-AXS, 5465 E. Cheryl Parkway, Madison, WI 53711-5373 USA.

(5) Zhu, W.; He, C.; Wu, X. Duan, C. Inorg. Chem. Commun. 2014, 39, 83-85. 